\title{
The extended autonomic system, dyshomeostasis, and COVID-19
}

\author{
David S. Goldstein ${ }^{1}[$
}

Received: 20 April 2020 / Accepted: 7 July 2020 / Published online: 22 July 2020

(c) This is a U.S. government work and its text is not subject to copyright protection in the United States; however, its text may be subject to foreign copyright protection 2020

\begin{abstract}
The pandemic viral illness COVID-19 is especially life-threatening in the elderly and in those with any of a variety of chronic medical conditions. This essay explores the possibility that the heightened risk may involve activation of the "extended autonomic system" (EAS). Traditionally, the autonomic nervous system has been viewed as consisting of the sympathetic nervous system, the parasympathetic nervous system, and the enteric nervous system. Over the past century, however, neuroendocrine and neuroimmune systems have come to the fore, justifying expansion of the meaning of "autonomic." Additional facets include the sympathetic adrenergic system, for which adrenaline is the key effector; the hypothalamic-pituitary-adrenocortical axis; arginine vasopressin (synonymous with anti-diuretic hormone); the renin-angiotensin-aldosterone system, with angiotensin II and aldosterone the main effectors; and cholinergic anti-inflammatory and sympathetic inflammasomal pathways. A hierarchical brain network - the "central autonomic network"- regulates these systems; embedded within it are components of the Chrousos/Gold "stress system." Acute, coordinated alterations in homeostatic settings (allostasis) can be crucial for surviving stressors such as traumatic hemorrhage, asphyxiation, and sepsis, which throughout human evolution have threatened homeostasis; however, intense or long-term EAS activation may cause harm. While required for appropriate responses in emergencies, EAS activation in the setting of chronically decreased homeostatic efficiencies (dyshomeostasis) may reduce thresholds for induction of destabilizing, lethal vicious cycles. Testable hypotheses derived from these concepts are that biomarkers of EAS activation correlate with clinical and pathophysiologic data and predict outcome in COVID-19 and that treatments targeting specific abnormalities identified in individual patients may be beneficial.
\end{abstract}

Keywords COVID-19 $\cdot$ Autonomic $\cdot$ Stress $\cdot$ Dyshomeostasis $\cdot$ Homeostasis $\cdot$ Catecholamines $\cdot$ Sympathetic $\cdot$ Adrenaline

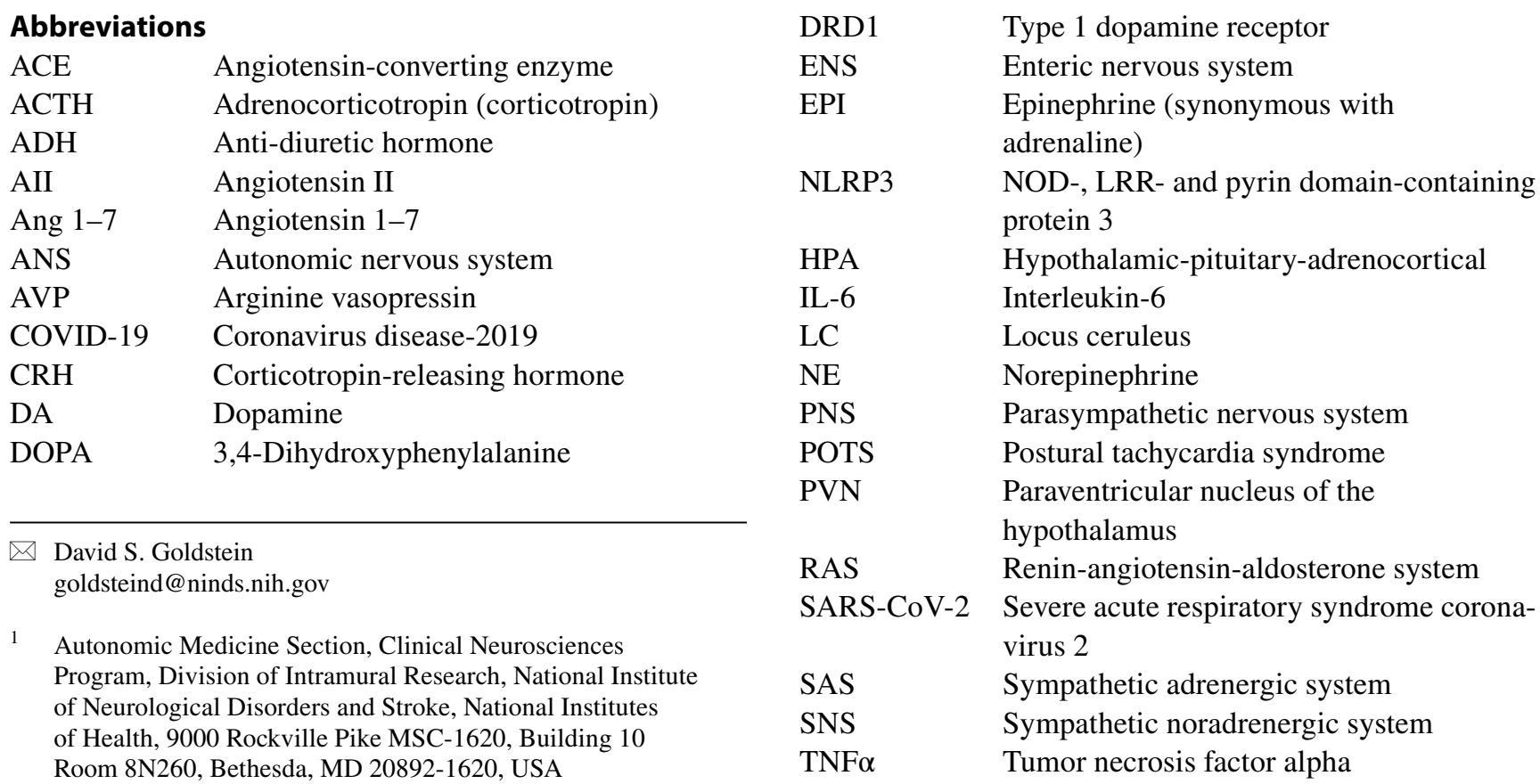




\section{Introduction}

Coronavirus disease-2019 (COVID-19), the acute illness caused by severe acute respiratory syndrome coronavirus 2 (SARS-CoV-2), is now pandemic, so far without effective treatments or vaccines. Biomedical researchers worldwide have shifted their focus urgently to COVID-19.

One of the major challenges posed by COVID-19 is that the disease is much more likely to be lethal in the elderly and in people with pre-existing chronic disorders such as diabetes, coronary artery disease, and obesity than in other populations. No conceptual framework has been offered to account for this phenomenon.

Pneumonitis and pulmonary dysfunction usually dominate the clinical picture, but it is by now clear that COVID19 importantly involves other body organs and systems, including the heart, gut, kidneys, and brain. The purpose of this essay is to convey a perspective that can account for the age-relatedness of COVID-19 mortality and the multi-organ - and therefore multi-disciplinary-aspects of the disease. The thesis is that both of these aspects may reflect dysautonomia, broadly defined as a condition where changes in functioning of one or more components of the autonomic nervous system adversely affect health.

The presentation begins with some integrative physiologic concepts-homeostasis, allostasis, dyshomeostasis, and stress-and introduces the notion of the "extended" autonomic system (EAS). The main take-home message is that biomarkers of EAS activation might predict outcome in COVID-19, and treatments targeting specific EAS abnormalities in individual patients might be more effective than one-size-fits-all approaches.

\section{Homeostasis}

The term "homeostasis" refers to the stability of the body's "inner world." In systems biology, homeostasis is an emergent phenomenon, but in integrative physiology homeostasis is a goal-it is the goal [71]. Thus, Claude Bernard, the founding father of integrative physiology, wrote, "The constancy of the internal environment is the condition for free and independent life...All the vital mechanisms, however varied they might be, always have one purpose, that of maintaining the integrity of the conditions of life within the internal environment" [12]. And Walter B. Cannon, who coined the word, homeostasis, wrote, "My first article of belief is based on the observation, almost universally confirmed in present knowledge, that what happens in our bodies is directed toward a useful end" [26].

A classic example of homeostasis is regulation of core temperature (Fig. 1, left). In response to cold
Homeostasis

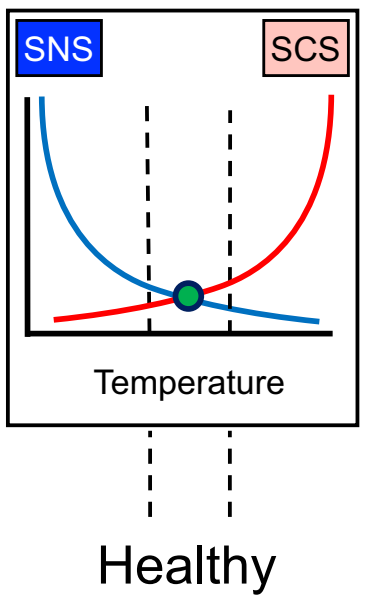

Allostasis

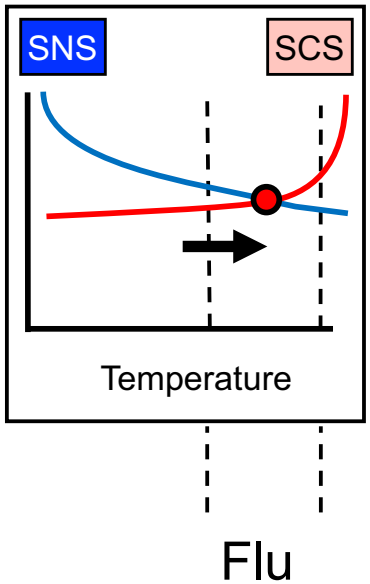

Fig. 1 From homeostasis to allostasis. In allostasis there is a shift in input-output curves for oppositely acting effectors (yellow and white), resulting in regulation of the monitored variable (in this case body temperature) at a different level. The acceptable bounds are the vertical dashed lines. A low-grade fever associated with a flu-like illness is an example of an allostatic state

exposure, sympathetic noradrenergic system (SNS) outflows increase, resulting in cutaneous vasoconstriction, shivering, and piloerection, all of which tend to maintain the core temperature. In response to heat exposure, sympathetic cholinergic system (SCS) outflows increase, evoking diaphoresis that tends to maintain the core temperature by evaporative heat loss.

\section{Allostasis}

Allostasis, from the Greek words for "other" and "standing still," refers to a shift in input-output curves (Fig. 1, right). A low-grade fever when an individual has a viral disease is an example of allostasis. The temperature is regulated, but at an altered thermostatic setting.

Allostatic adjustments use up more energy than do homeostatic adjustments, but normally allostatic states are temporary and beneficial (whether a fever is helpful in fighting off a viral illness has been debated for decades [130]). Once the individual recovers, the input-output curves revert to those before the acute illness, with no apparent harm done.

Allostatic states, however, also increase wear and tear on both the effectors and the target organs-allostatic load [74]. Declining homeostatic efficiencies (dyshomeostasis) associated with aging and chronic disorders can prolong or intensify the accumulation of allostatic load and eventually decrease thresholds for a variety of vicious cycles (positive feedback loops) that can be lethal. 


\section{Dyshomeostasis in the elderly}

That resilience declines with aging is part of humankind's evolutionary heritage. In his The Wisdom of the Body Walter B. Cannon devoted an entire chapter to this phenomenon. Cannon summarized already substantial literature that with aging the abilities to maintain body temperature, glucose, blood $\mathrm{pH}$, and circulatory-respiratory delivery of oxygenated blood under baseline conditions are preserved, but for each of these vital functions there are decreased abilities to keep appropriate levels during stress-e.g., heat or cold exposure, glucose ingestion, and exercise.

This viewpoint from about a century ago still applies. For instance, during cooling by intravenous infusion of cold saline, older people 55-72 years old have larger decreases in core temperature and smaller increments in plasma norepinephrine (NE) levels, systemic vascular resistance, and heat generation than younger people 18-23 years old [58].

After taking a high carbohydrate diet, in young adults postprandial plasma adrenaline (epinephrine, EPI) levels follow a biphasic diurnal pattern that is inversely related to glucose and insulin levels. Aging is associated with a dysregulation of this response [139], and insulin sensitivity declines with aging [171].

Baroreflex sensitivity, and consequently the ability to keep blood pressure within bounds, also decreases as a function of age, in a manner associated with hypertension [16]. The rate of pulse-synchronous bursts of skeletal muscle sympathetic nerve traffic increases with aging [170]; however, arterial baroreflex control of muscle sympathetic nerve traffic [117] and of cardiovagal outflow is decreased in the elderly [16].

Plasma NE levels, NE responses to stress, skeletal muscle sympathetic outflow, and cardiac NE spillover all increase with aging [44, 54, 134], probably from a combination of decreased neuronal reuptake of NE and increased sympathetic nerve traffic. For a given amount of reflexively increased sympathetic outflow, however, there is a blunted vasoconstrictor response [44]. Responses of cardiac NE spillover to exercise are similar in elderly vs. young men, but this is due to an aging-related decline in neuronal reuptake of released NE, meaning that the increment in cardiac sympathetic outflow probably is blunted [54].

The ability of catecholamines to break down triglycerides to free fatty acids decreases with aging. This may increase susceptibilities to exercise intolerance, decrease ability to maintain core body temperature during cold exposure, and reduce ability to survive starvation, as well as increase visceral adiposity and indolence.

As people age the efficiency of immune responsiveness also generally declines. Depending on genetics, epigenetics, and life experiences, "immune age" can be estimated and is correlated with all-cause mortality [3]. Unbiased whole-transcriptome analysis of adipose macrophages has revealed that aging upregulates the gene encoding monoamine oxidase-A (MAO-A) in an NLRP3 inflammasomedependent manner, and MAO-A inhibition restores NEinduced lipolysis [22].

\section{The extended autonomic system (EAS)}

\section{Autonomic neuroendocrine systems}

The autonomic nervous system conceptualized by Langley in the early 20th century has three components-the sympathetic nervous system, the parasympathetic nervous system, and the enteric nervous system [102]. Walter B. Cannon added a neuroendocrine component, here called the sympathetic adrenergic system (SAS), in which EPI is the hormonal chemical messenger [27, 28]. Cannon taught that the sympathetic nervous system and adrenal gland act together in emergencies to maintain homeostasis [23, 24]. This view is still widely held, although by now there is abundant evidence that the neuronal component, here called the sympathetic noradrenergic system (SNS), and the hormonal component, the SAS, are constitutively active [101] and participate in even the mundane aspects of daily life.

Neuroendocrine systems expand the meaning of "autonomic." Modern neuroendocrinology refers specifically to peptides secreted by hypothalamic neurons into the circulation. Even in this sense the neuroendocrine and autonomic systems interact. For instance, thyroidectomy, which increases thyrotropin secretion, also increases plasma levels of the SNS neurotransmitter NE [61]. Release of corticotropin-releasing hormone $(\mathrm{CRH})$ in the brain concurrently increases SNS and SAS outflows [18, 91]. Infusion of the beta-adrenoceptor agonist isoproterenol into humans decreases plasma levels of both corticotropin (ACTH) and EPI [52]; subacute glucocorticoid treatment with prednisone decreases directly recorded skeletal muscle sympathetic outflow [68]. Both hypopituitarism and adrenocortical failure decrease plasma EPI and increase plasma NE levels [152, 172]. Arginine vasopressin (AVP) inhibits SNS responses to hemorrhage [85]. Corticosteroid synthesis by cultured adrenocortical cells is increased ten-fold by co-culture with adrenomedullary chromaffin cells [82]. In general, across a variety of stressors, plasma EPI responses are more closely tied to ACTH responses than to NE responses [73].

\section{Autonomic neuroimmunology}

Another extension of the concept of autonomic relates to the immune system. The field of neuroimmunology focuses on interactions between the nervous system and immune functions. Anti-inflammation exerted by adrenocortical steroids 
was fundamental in Selye's stress theory [159], discussed below. A much more modern example of autonomic-immune interactions is regulation of cytokines and the "inflammasome" by the vagus nerve $[97,191]$. The inflammasome concept is based on the NOD-, LRR-, and pyrin domain-containing protein 3, or NLPR3 [173]. NLPR3 is conceptualized to be an intracellular sensor that can detect a wide variety of microbes, including RNA viruses. NLRP3 inflammasome formation leads to release of the proinflammatory cytokines IL-1 beta and IL-18 and to cell death by pyroptosis. Pyroptosis is a form of programmed cell death that may remove intracellular viral replication niches in the tissue.

The cytokine IL- 6 not only activates the HPA axis but also directly stimulates production of aldosterone, cortisol, and androgenic steroids [137]. In conscious, unrestrained rats, TNF $\alpha$ administration increases plasma levels of glucagon, corticosterone, ACTH, NE, and 3,4-dihydroxyphenylglycol (DHPG, the main neuronal metabolite of NE) [43].

It has been proposed that overactivity of myocardial beta-adrenoceptors by SNS activation exerts proinflammatory effects [94]. There actually are three types of peripheral catecholamine system in humans-the SNS, where NE is the locally acting neurotransmitter, the SAS, where EPI is the hormone, and the DOPA-dopamine (DA) autocrine-paracrine system [75], in which DA is produced in, released from, and acts locally on parenchymal cells that take up DOPA from the circulation and decarboxylate the amino acid to form the catecholamine. The latter mechanism is by definition an activity of "APUD" cells (APUD standing for amine precursor uptake and decarboxylation) that release polypeptide hormones in a diffuse neuroendocrine system [124].

In primary human monocytes, alpha-1 adrenoceptor stimulation by phenylephrine has been reported to suppress the NLPR3 inflammasome [87]; however, the same drug has been reported to induce cardiac dysfunction and inflammation in vivo as evidenced by increased expression of IL-6 and NLRP3 [195]. Across a variety of stressful situations, increases in EPI levels are associated with elevations of the proinflammatory cytokine IL-6 [41, 84, 90, 96, 100, 135, 141]; however, bases for this relationship have not been systemically studied.

The sources of endogenous DA outside the brain are relatively poorly understood. In the kidneys DA is formed from uptake and decarboxylation of circulating DOPA [190] by proximal tubular cells and acts as an autocrine-paracrine substance [75] that promotes natriuresis [8]. In patients with decompensated congestive heart failure, levodopa treatment increases urinary sodium excretion [77]. Whether intravenously administered DOPA or DA affects the NLRP3 inflammasome is unknown.
Proinflammatory cytokines increase expression of $\mathrm{CRH}$ and AVP in the hypothalamus [34], probably via vagal afferents [64]. In critically ill patients, non-survivors have been reported to have higher ACTH levels in response to exogenously administered CRH and longer release of cortisol, associated with higher levels of IL-6 and IL-8 [46].

In the cholinergic anti-inflammatory pathway [182], efferent nerve traffic from the dorsal motor nucleus of the vagus nerve increases delivery of acetylcholine to $\alpha 7$ nicotinic receptor subunits on celiac-superior mesenteric post-ganglionic neurons that terminate in the spleen and act on splenic immune cells to decrease TNF $\alpha$ generation $[97,150]$.

\section{Stress and the "stress system"}

Hans Selye defined stress as the non-specific response of the body to any demand imposed upon it [161]. In line with Selye's conceptualization, in the 1990s George Chrousos and Philip Gold at the NIH proposed the existence of a central stress system, activation of which would elicit a "stress syndrome" [36, 168]. Key elements of the stress system as originally proposed were the paraventricular nucleus (PVN) of the hypothalamus, from which CRH is derived, and the locus ceruleus (LC) of the pons, from which NE in most of the brain is derived (Fig. 2, left panel). CRH drives pituitary release of ACTH in the HPA axis.

The original Chrousos/Gold stress system has required modification. For one thing, arginine vasopressin (AVP, synonymous with anti-diuretic hormone, $\mathrm{ADH}$ ) is another neuroendocrine factor derived from the PVN. For another, the LC does not directly drive SNS or SAS outflows; several other brainstem sites do [40, 48, 49, 79, 125]. A more complex schema embeds the stress system within the "central autonomic network" [10] (Fig. 2, right panel). The central autonomic network is the source of outflows to components of the autonomic nervous system, including the SNS, for which NE is the neurotransmitter, the SAS, for which EPI is the hormone, and the parasympathetic nervous system (PNS), for which acetylcholine is the neurotransmitter [70].

Selye also conceptualized the "General Adaptation Syndrome" [160]. By this he was referring to three stages. The stages were alarm, resistance, and exhaustion, and the three pathologic consequences were adrenal enlargement, gastric bleeding, and "involution of the thymico-lymphatic apparatus." The alarm stage is acute and in the present vocabulary would include HPA, SNS, and SAS activation. The resistance stage, which Selye theorized can go on for variable periods of time, is adaptive and may correspond to an allostatic state. Accumulation of allostatic load decreases thresholds for induction of vicious cycles that usher in the exhaustion stage, the harbinger of imminent organismic death. 

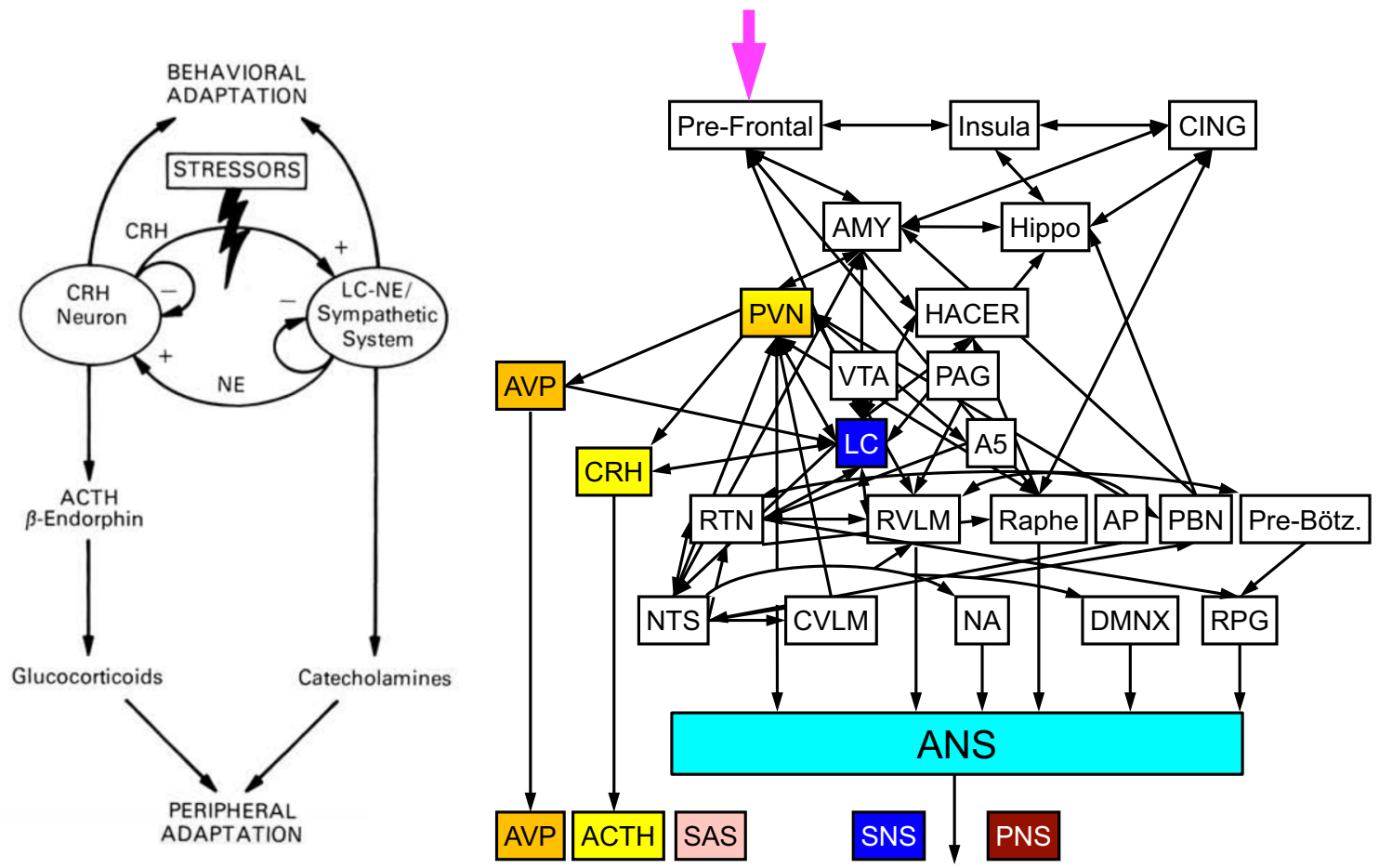

Fig. 2 Central stress systems. The concept diagram on the left (reproduced with permission of the American College of Physicians) shows the Chrousos and Gold model of "the central stress system." The concept diagram on the right relates the central stress system to the central autonomic network. CING cingulate cortex, $A M Y$ amygdala, Hippo hippocampus, $P V N$ paraventricular nucleus of the hypothalamus, HACER hypothalamic area controlling emotional responses, $A V P$ arginine vasopressin (same as anti), $C R H$ corticotropin-releasing hormone, VTA ventral tegmental area, $P A G$ periaqueductal gray, $L C$

\section{Effects of EAS activation}

\section{The sympathetic adrenergic system (SAS)}

EPI is a remarkably potent hormone that exerts numerous bodily effects. Most of these are well known, and so only aspects potentially relevant to COVID-19 are noted here. EPI-induced vasoconstriction in the splanchnic bed and kidneys decreases gastrointestinal and renal perfusion. EPI increases sweating [132], and the combination of cutaneous vasoconstriction and adrenergic sweating may explain the "cold sweat" that characterizes people in shock. EPI increases cardiac rate and contractility [121], increasing cardiac output, and increases spontaneous electrical depolarization and the electrocardiographic QTc interval [169].

EPI also increases serum glucose levels [42] by multiple mechanisms, including anti-insulin effects, breakdown of hepatic glycogen, stimulation of hepatic gluconeogenesis [163], and stimulation of pancreatic secretion of glucagon [83]. locus ceruleus, A5 A5 noradrenergic cell group, $R T N$ retrotrapezoid nucleus, $R V L M$ rostral ventrolateral medulla, $A P$ area postrema, $P B N$ parabrachial nucleus, Pre-Botz. pre-Botzinger complex, NTS nucleus of the solitary tract, $C V L M$ caudal ventrolateral medulla, $N A$ nucleus ambiguus, $D M N X$ dorsal motor nucleus of the vagus nerve, $R P G$ respiratory pattern generator, $A C T H$ adrenocorticotrophic hormone (corticotropin), ANS autonomic nervous system, SNS sympathetic noradrenergic system (norepinephrine), SAS sympathetic adrenergic system (adrenaline), PNS parasympathetic nervous system (acetylcholine)

EPI increases hepatic breakdown of lipids to free fatty acids, generating heat, and evokes thermogenesis via uncoupling protein-1 in brown adipose tissue [179].

EPI activates platelets [122], via occupation of alpha-2 adrenoceptors [103, 104].

EPI stimulates the renin-angiotensin-aldosterone system (RAS) [76]. Angiotensin II is a potent vasoconstrictor and in concert with EPI would be expected to augment splanchnic and renal vascular resistance. Aldosterone, the body's main mineralocorticoid, promotes sodium reabsorption and renal potassium loss.

EPI decreases serum potassium and magnesium levels [42, 129] via augmentation of $\mathrm{Na} / \mathrm{K}$ ATPases that mediate transmembrane cation influx [9]. The fall in serum potassium may help to explain a dissociation of stimulated plasma renin activity and less clear effects on plasma aldosterone [99].

Finally, EPI intensifies the negative emotional experience of fear [167], probably via afferent information to the brain from physiologic changes exerted by occupation of adrenoceptors. 


\section{The sympathetic noradrenergic system (SNS)}

The SNS is tonically active [101] and plays key roles in patterned alterations in the distribution of the cardiac output among the vascular beds during activities of daily life such as standing up [101], eating a meal, mild exercise [158], the Valsalva maneuver, and adjustments to altered environmental temperatures. In addition to the cardiovascular system, SNS outflows to the irises, sweat glands, gastrointestinal tract, and pancreas, and kidneys play important "housekeeping" roles.

It is important to keep in mind that NE is a neurotransmitter, not a hormone. Because of this regional heterogeneity and different roles, measuring plasma NE levels can be uninformative. For instance, in resting humans hypoxia increases skeletal muscle sympathetic outflow without increasing plasma NE [151].

Increases in renal sympathetic outflow promote sodium reabsorption by proximal tubular cells [66]. Both NE and EPI increase cellular uptake of potassium and therefore tend to decrease serum potassium levels [37].
Arginine vasopressin/anti-diuretic hormone (AVP/ADH)

AVP acting as ADH promotes renal retention of water. In acute illnesses this can manifest with decreased serum osmolality and hyponatremia [59]. AVP acting as a pressor contributes to vasoconstriction and blood pressure; however, the effects may be masked by other determinants of systemic vascular resistance. In addition, in the brain AVP shifts the arterial baroreflex to lower blood pressures, and the maximum amount of sympathetic activation for a given decrease in blood pressure is reduced [85].

\section{The hypothalamic-pituitary-adrenocortical (HPA) axis}

As noted above, the HPA axis has been viewed as the main effector of the central stress system. Regulation of the HPA axis is more complicated than that depicted by Selye's theory or the Chrousos/Gold model. For instance, in critically ill patients there is decreased clearance of circulating cortisol $[14,138]$. This may augment negative feedback regulation of CRH and explain attenuated ACTH responses. Studies

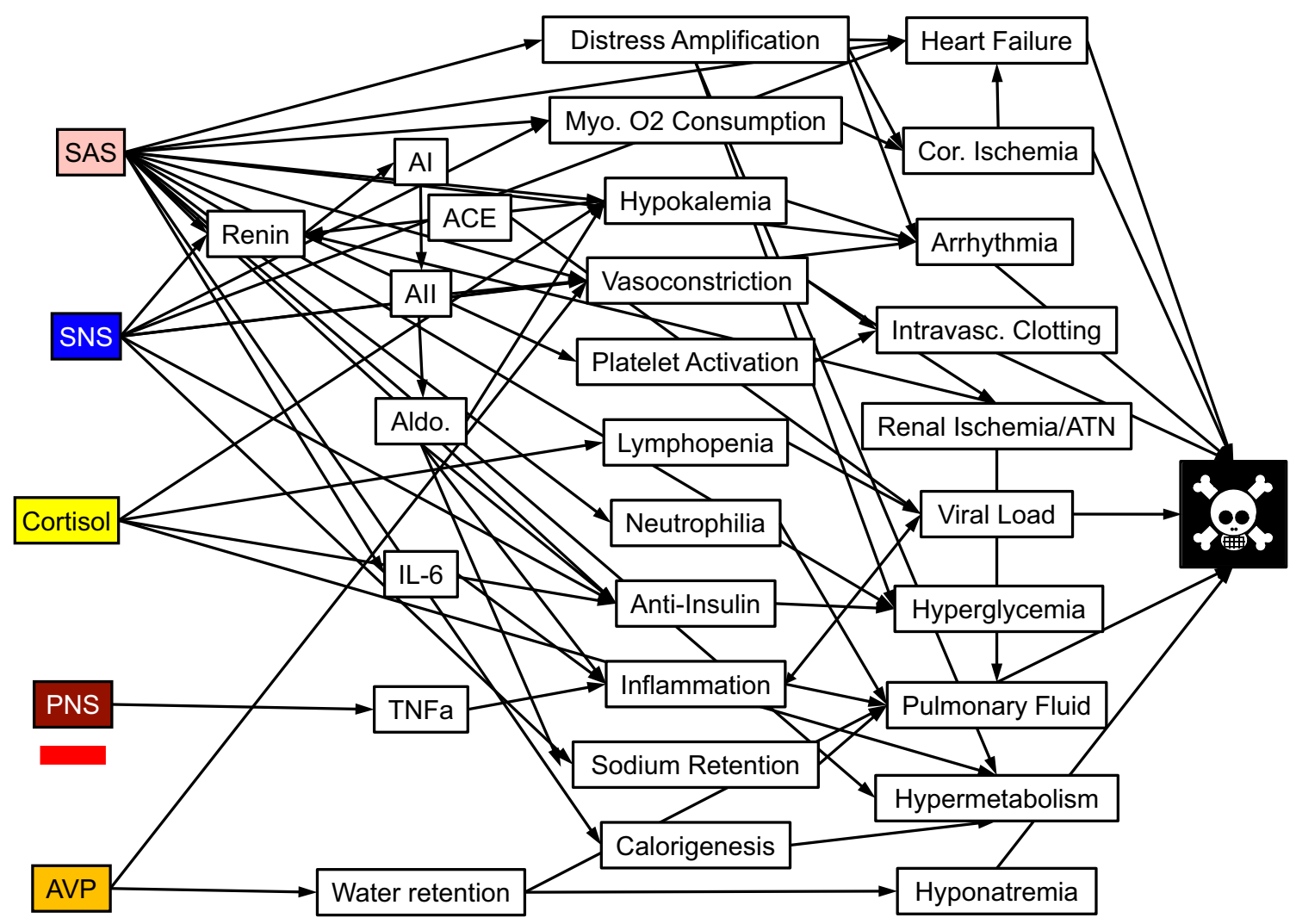

Fig. 3 From EAS system activation to dyshomeostasis to death. Five effector components of the EAS are on the left. Intervening variables are in the center. Factors contributing the critical illness or death are on the right. The red bar under PNS indicates PNS inhibition. AI angiotensin I, $A C E$ angiotensin-converting enzyme, $A I I$ angiotensin II, Aldo aldosterone, $A T N$ acute tubular necrosis, $I L-6$ interleukein 6, Myo. myocardial, Cor. coronary, TNFa tumor necrosis factor alpha 
involving real-time dynamics of glucocorticoid hormones and glucocorticoid receptor function indicate pulsatility of the HPA axis and a continuous dynamic equilibrium [111].

In patients treated with intravenous methylprednisolone for multiple sclerosis flareups, there are diverse acute symptomatic side effects, including abdominal pain, nausea, and vomiting, disturbed sleep, and neurobehavioral changes such as confusion, irritability, and restlessness [92]. Common clinical laboratory findings are hyperglycemia, hypokalemia, increased blood pressure, and anti-inflammation. All these aspects may be relevant to neurobehavioral and clinical laboratory abnormalities in COVID-19 because of the frequent use of high-dose steroids as part of management in the intensive care setting.

\section{The parasympathetic nervous system (PNS)}

Unlike other autonomic effectors, the PNS is active in situations that are not distressing and tend to build up rather than use up energy [70]. When the central stress system is activated, PNS outflows generally decrease (red negative sign in Fig. 3). Manifestations of PNS inhibition include tachycardia, decreased gastrointestinal motility, decreased production of saliva and tears, and decreased urinary bladder tone. Vagal stimulation inhibits production of the cytokine $\mathrm{TNF} \alpha[106,200]$.

\section{The renin-angiotensin-aldosterone system (RAS)}

The renin-angiotensin-aldosterone system (RAS) plays major roles in homeostasis of extracellular fluid volume, blood pressure, electrolytes, and immune functions. The main determinants of release of the proteolytic enzyme renin are SNS and SAS activation (acting through beta-a adrenoceptors), decreased renal perfusion, and decreased sodium delivery to the distal tubules of the kidney. Renin cleaves the circulating protein angiotensinogen to form angiotensin I. Angiotensin I is converted to angiotensin II (AII) by angiotensin-converting enzyme (ACE), which is especially abundant in vascular endothelium of the lungs. AII exerts numerous effects. It is a potent vasoconstrictor and augments adrenocortical secretion of aldosterone, the body's main salt-retaining steroid. In adrenomedullary cells AII stimulates secretion of catecholamines via increased cytosolic ionized calcium [203]. In the brain, probably via a separate local RAS, AII evokes AVP release and drinking behavior and increases sympathetic outflows. ACE2, a homolog of ACE, converts AII to angiotensin 1-7 (Ang 1-7), which opposes the effects of AII. Thus, ACE2 inhibition would be expected to build up AII. Relevant to the present discussion, the SARS-CoV-2 virus enters cells via binding to ACE2.

\section{The EAS and biomarkers of risk, with applications to COVID-19}

One of the lessons of the COVID-19 pandemic, and a source of anxiety and worry, is that it seems impossible to predict who among the infected will suffer from rapid evolution to acute respiratory distress syndrome and multi-organ failure. This section describes clinical and laboratory biomarkers that may indicate a high risk of such a transition and are related to altered EAS functions.

There are references here to sudden, unexpected health catastrophes-earthquakes, acute coronary syndromes and stress-related cardiomyopathy (takotsubo cardiomyopathy), and previous viral epidemics (SARS, Middle East respiratory syndrome). To the extent published information is available, each factor is applied to COVID- 19 .

\section{Age}

Analyses of medical records from before vs. after natural catastrophes such as Hurricane Katrina in 2005 [1, 19] and the 2011 earthquake/tsunami in Japan $[39,131]$ have indicated disproportionately increased morbidity and mortality among the elderly [118]. This has not been a universal finding, however [183].

The high risk of serious illness or lethality in the elderly from COVID-19 is quite clear. According to the US Centers for Disease Control, hospitalizations, intensive care unit admissions, and case fatality rates are age-related [143]. The case-fatality rate in people $75-84$ years old is about 10 times that in people 55-64 years old and about 40 times that in people 20-22 years old.

\section{Hyperglycemia}

Hyperglycemia is a common feature of critical illness, even in individuals without a history of diabetes [65]. In patients with acute, severe head injury, high serum EPI and NE levels have been associated with hyperglycemia, worse Glasgow coma scores, and poor survival [199]. After the Kobe earthquake of 1995, hemoglobin A1c levels and high scores on the General Health Questionnaire were especially evident in diabetic patients who had severe damage to their homes or who had relatives who were killed or injured, indicating long-term effects of the acute stress exposure [88]. After the East Japan earthquake/tsunami in 2011, among diabetic patients followed in a diabetes clinic somatic symptoms and sleep disturbances or anxiety were independently associated with worse glycemic control [60].

In acute coronary syndromes, hyperglycemia upon admission is common regardless of a history of diabetes and is associated with both increased mortality [98] and a variety 
of morbidities including ventricular tachycardia/fibrillation, atrial fibrillation, advanced degrees of atrioventricular block, and pulmonary edema [51] and poor outcome after emergency coronary artery bypass grafting [177]. In non-diabetic patients admitted for acute myocardial infarction, concentrations of cortisol, EPI, and NE are the main correlates of circulating glucose concentrations [133]. High glucose levels are an adverse prognostic factor in patients admitting for ST elevation myocardial infarction (STEMI), regardless of the occurrence of diabetes mellitus [162]. Both acute mortality and the subacute event rate are increased in patients with high admission glucose levels [47, 147]. In the pre-hospital phase of cardiac arrest with return of spontaneous circulation, hyperglycemia occurs commonly and is associated with increased mortality [185].

In patients with COVID-19 hyperglycemia at the time of hospitalization is common and related to adverse prognosis [13, 156, 164, 193]. Patients with "new" diabetes noted during the hospitalization have if anything poorer outcomes than those with an already established diagnosis [107].

\section{Hypokalemia}

EPI administration decreases serum potassium levels [169] via agonist effects at beta- 2 adrenoceptors [17, 42, 93]. After the Sichuan earthquake in 2008, hypokalemia was associated with ventricular tachyarrhythmias in the ensuing month [202].

In hospitalized COVID-19 patients hypokalemia occurs commonly and is also associated with increased mortality [31]. Low serum potassium may reflect augmented sodium/ potassium exchange in the kidneys mediated by aldosterone as well as endogenous and exogenously administered EPI.

\section{Hyponatremia}

Hyponatremia often occurs in critical illnesses [59]. After the Sichuan earthquake of 2008 in Japan and the Bam earthquake of 2003 in Iran there was a high frequency of hyponatremia, and the hyponatremia was an independent mortal risk factor [155, 201]. Among patients with congestive heart failure, ADH levels are increased in a manner associated with hyponatremia [146, 174].

In patients with COVID-19 hyponatremia can be an early or isolated finding [5, 21, 81]. Hyponatremia has been ascribed to inappropriate secretion of $\mathrm{ADH}[2,35]$. It is unknown whether hyponatremia is an independent predictor of outcome in COVID-19.

\section{Electrocardiographic Abnormalities}

Tachycardia, electrocardiographic changes, and abnormal heart rate variability in the frequency domain occur commonly during catastrophes and in severe illnesses. At the time of the Taiwan earthquake of 1999, 15 patients happened to be undergoing 24-h Holter monitoring, and heart rate variability data were analyzed in the time and frequency domains. Heart rate and the ratio of low frequency/high frequency $(\mathrm{LF} / \mathrm{HF})$ power increased after the earthquake and were attributed to PNS withdrawal [112]. After the Great Hanshin Earthquake of 1995, there was an increased frequency of deep negative electrocardiographic $\mathrm{T}$ waves and accelerated washout of cardiac ${ }^{123}$ I-metaiodobenzylguanidine-derived radioactivity, interpreted as indicating increased cardiac sympathetic outflow [196]. The 2008 Sichuan earthquake was associated with an increased frequency of hemodynamically unstable ventricular tachyarrhythmias [202]. On the other hand, the 2011 Christchurch earthquakes were not associated with increased ventricular arrhythmias, based on analysis of implanted defibrillator diagnostics [30], while in the same year, after the East Japan earthquake there was an increased incidence of tachyarrhythmias in patients with implanted cardiac devices [128]. After the East Azarbaijan earthquake in 2012 there was a reported increased likelihood of arrhythmic events associated with anxiety in patients with implanted defibrillators [145].

In stress-related acute heart failure, prolongation of the QTc interval occurs regardless of left ventricular apical ballooning [188] (see the section below about takotsubo cardiomyopathy).

EPI increases the electrocardiographic QTc interval [42, 169]. In acute stroke, the most common new electrocardiographic abnormality is QTc prolongation [20, 69].

In hospitalized patients with COVID-19 several studies have noted prolongation of the QTc interval; however, interpreting this abnormality has been difficult because of the possibility of iatrogenicity from treatment with chloroquine or hydroxychloroquine [95]. No studies have reported on power spectral analysis of heart rate variability, in either the time or frequency domains. There are numerous mechanisms by which SNS or SAS activation could precipitate cardiac arrhythmias [50]. None of these has been explored specifically in COVID-19-related research.

\section{Immune functions}

Central stress system activation would be expected to produce lymphopenia from HPA axis stimulation. Neutrophilia may reflect effects of glucocorticoids [181] or catecholamines. In healthy volunteers adrenaline infusion acutely evokes leukocytosis, neutrophilia, and lymphocytosis and increases the activity and numbers of natural killer cells [181]. The effects of circulating catecholamines depend on the types of occupied adrenoceptors. Adrenaline, which stimulates both types of adrenoceptor, results more in betaadrenoreceptor-mediated effects [11]. 
By now it has been widely publicized and generally accepted that COVID-19 patients are variably susceptible to "cytokine storm." Bases for this variability are unknown. In asymptomatic individuals with COVID-19 there seems to be less active immune responses than in symptomatic individuals [115]. It has been reported that within 19 days of symptom onset, all patients test positive for antiviral immunoglobulin-G (IgG) [114]. These findings suggest that symptomatic patients have more active immune responses.

COVID-19 patients have been reported to have lymphopenia [55, 113], related to decreases in natural killer cells and $\mathrm{T}$ cell populations [45]. The numbers of total $\mathrm{T}$ cells and $\mathrm{CD} 4(+)$ and $\mathrm{CD} 8(+)$ T cells are dramatically reduced, associated with increased serum IL-6, IL-10, and TNF-alpha concentrations and poor survival [45]. Meanwhile, there tends to be neutrophilia $[113,192]$ and increased neutrophil extracellular traps (networks of extracellular fibers mainly containing neutrophil DNA that bind pathogens), associated with increased COVID-19 mortality [180].

\section{Heart failure}

\section{Dyshomeostasis and heart failure}

As intrinsic cardiac pumping efficiency declines, the SNS is activated $[89,119,178]$. At first, the increase in SNS outflow seems to be confined to the heart [153]. Once cardiac pump function declines to below a certain level despite maximal SNS stimulation, blood backs up into the pulmonary veins, bringing on pulmonary edema. The patient becomes short of breath, and in a distress response experiences the classic "feeling of impending doom" that has been associated from time immemorial with massive activation of the SAS and high circulating EPI levels. Rather than augmenting left ventricular myocardial contractility, EPI can be toxic to myocardial cells. Myocardial contractility could decrease further, and "stress cardiopathy" could set in, worsening the pulmonary edema.

Low LF power is an independent predictor of sudden death in heart failure patients [63]. LF power seems to be less of a marker of cardiac sympathetic outflow than of the ability to modulate that outflow via baroreflexes [72, 144, 166]. Therefore, the absence of LF power in severe heart failure may represent baroreflex failure. Whether severely ill COVID-19 patients have low LF power is unknown.

\section{Stress-related cardiomyopathy}

A particular type of acute heart failure involving nonischemic myocardial stunning [189] has been called takotsubo cardiomyopathy [94], because left ventricular apical ballooning in this syndrome gives the radiographic appearance of a takotsubo, a type of Japanese pottery for catching octopuses. Takotsubo cardiomyopathy is especially common in post-menopausal women, for unknown reasons. Heart failure with apical akinesia can occur in disorders involving high circulating levels of catecholamines such as pheochromocytoma [62].

After the 2004 Niigata earthquake, two patients were reported who had takotsubo cardiomyopathy [175]. Both had stress-associated chest pain, giant $\mathrm{T}$ waves in the electrocardiogram, and echocardiographic apical hypokinesia, without evidence of coronary artery disease during cardiac catheterization. Both patients had accelerated loss of ${ }^{123}$ I-metaiodobenzylguanidine-( ${ }^{123} \mathrm{I}$-MIBG)-derived radioactivity, consistent with increased sympathetically mediated exocytosis from myocardial sympathetic nerves. After the 1995 Hanshin earthquake, there was an increased incidence of patients with deep negative $\mathrm{T}$ waves, also associated with accelerated loss of ${ }^{123}$ I-MIBG-derived radioactivity [196]. After the 2011 East Japanese earthquake/tsunami there was an increased incidence of acute decompensated heart failure in the affected geographic region [127]. The frequency of atrial fibrillation was also increased [126]. Patients admitted to the hospital after the earthquake were characterized by older age, systolic hypertension, infection, increased B-type natriuretic peptide and C-reactive protein (respective biomarkers of heart failure and inflammation), and decreased glomerular filtration rate [197].

In COVID-19 patients heart failure is a major concern. Patients with pre-existing cardiovascular disease are more likely to be infected with SARS-CoV-2 and are more likely to develop severe symptoms. There are several potential mechanisms. Myocarditis can result directly from local infection with SARS-CoV-2 and the local immune response [165]. ACE2 receptor disruption may cause damage by preventing conversion of AII to Ang (1-7) [7]. Toxic effects of endogenous or exogenous catecholamines may evoke a takotsubo cardiopathy pattern $[67,120,123,136,148]$. There may be endothelial or microvascular dysfunction or instability of coronary arterial plaque [80].

In heart failure cardiac NE stores become depleted [32]. This is likely from greater NE release with escape of neuronal reuptake compared to catecholamine biosynthesis via tyrosine hydroxylase [53]. The depletion of NE stores in the failing human heart attenuates the ability of indirect-acting sympathomimetic amines to provide inotropic support [142].

\section{Intravascular clotting}

In the COVID-19 pandemic there has been an unexpectedly high frequency of intravascular clotting, manifested by deep vein thrombophlebitis, pulmonary embolism, myocardial infarction, or stroke. It has been proposed that an imbalance between coagulation and inflammation results in 
a hypercoagulable state. Thrombosis initiated by the innate immune system may limit SARS-CoV-2 dissemination, but aberrant activation of this system could cause endothelial injury, with dysregulation of fibrinolysis and thrombosis [38]. The roles of neutrophilia, neutrophil extracellular traps, platelet activation, and proinflammatory cytokines are a subject matter of active investigation and ongoing clinical trials.

One should bear in mind that adrenaline is a potent hemostatic agent, not only because of vasoconstriction but also because of promotion of platelet aggregation [104, 122], at least partly via agonism at alpha-2 adrenoceptors $[4,103]$. Whether this contributes to intravascular clotting in COVID19 is unknown.

\section{Central nervous system}

COVID-19 is associated with a variety of central nervous system abnormalities, including stroke, encephalopathy, encephalitis, anosmia, anorexia, headache, nausea, and delerium [184]. A meta-analysis of literature from prior epidemics (SARS, Middle East respiratory syndrome) noted high frequencies of confusion, depressed mood, anxiety, impaired memory, and insomnia [149]. It has been proposed that the SARS-CoV-2 virus may invade the brainstem and alter functions of medullary cardiorespiratory centers [110].

In patients with Parkinson's disease COVID-19 worsens motor and non-motor symptoms, with urinary abnormalities and fatigue being prominent [110]. In this study symptoms and signs one might ascribe to autonomic failure were unaffected. Serum neurofilament light chain levels, a biomarker of axonal damage, have been reported to be increased in COVID-19 patients [116]. Although patients with increased serum neurofilament light chain levels have been reported to be more likely to require intubation, the levels seem unrelated to neurologic symptoms.

There have been no reports about brain regions or pathways of the central autonomic network in COVID-19, although one may reasonably speculate that involvement of the medullary nucleus of the solitary tract or dorsal motor nucleus of the vagus nerve predisposes to symptoms such as nausea, vomiting, and loss of appetite [33].

The dysautonomia postural tachycardia syndrome (POTS) can be a consequence of viral illnesses $[56,157]$ and may have an autoimmune component $[78,108,154]$. There are substantial concerns-but no published data-about possibly increased risk from COVID-19 in people with POTS. Conversely, one may anticipate an increased incidence of POTS in COVID-19 patients.

One may also anticipate a high frequency of post-traumatic stress disorder [57, 194], which could be related to EAS activation [140].

\section{EAS activation in COVID-19 may be a double-edged sword}

The direct and indirect effects of EAS activation can be understood in terms of enhancing survival in life-threatening emergencies that have threatened homeostasis throughout mammalian evolution, such as asphyxiation, hemorrhage, starvation, salt deprivation, water deprivation, exposure to extremes of temperature, and "fight-or-flight" encounters $[24,25]$.

This activation may come at a cost. Among other things, activation of the extended ANS increases myocardial oxygen consumption and glucose levels, uses up energy, decreases thresholds for arrhythmias, induces hypokalemia and hyponatremia, can promote renal ischemic injury and intravascular thrombosis, and can evoke a form of stress cardiopathy [189]. Moreover, imbalances in the inflammasome system could contribute to cytokine "storm."

In several ways, in critically ill patients physiologic negative feedback loops could give way to pathophysiologic positive feedback loops. Within a sometimes surprisingly short period of time from the onset of symptoms, the patient could die-within minutes because of a catecholamine-evoked ventricular arrhythmia, hours because of intractable pulmonary edema, or days because of critically decreased perfusion of body organs such as the kidneys.

\section{Biomarkers predicting COVID-19 mortality}

Hyperglycemia, hypokalemia, hyponatremia, prolongation of the electrocardiographic QTc interval, arrhythmias, hemodynamic instability, takotsubo cardiopathy, and neurobehavioral manifestations suggest contributions of the EAS to morbidity and mortality in COVID-19; however, all these indices are indirect and complexly determined.

Quantitative indices of EAS activation such as increases in plasma catecholamines, ACTH, AVP, and AII levels could provide valuable biomarkers by which to test whether EAS involvement explains the high mortality associated with aging and chronic disorders of regulation in COVID-19. To date, no reports have described levels of any of these compounds in COVID-19 patients. A recent correspondence noted associations of both elevated neutrophil/lymphocyte ratios and cortisol levels with decreased survival in COVID19 patients [176].

\section{Treatment implications}

In COVID-19 patients who have evidence of EAS activation, treatment with already existing drugs such as the benzodiazepine alprazolam $[15,86]$, the $\mathrm{CRH}-1$ receptor antagonist antalarmin [6], the alpha-2 adrenoceptor agonist 
dexmedetomidine [109, 187], a beta-1 adrenoceptor blocker, an IL-6 inhibitor (tocilizumab), or even DOPA or DA might prevent positive feedback loops and improve survival. Some of these are undergoing clinical trials now.

Given that adrenaline promotes platelet aggregation, treatment with dexmedetomidine might be risky in COVID19 patients with intravascular clotting.

DA, via the type-1 DA receptor-1 (DRD1) and cyclic AMP signaling, inhibits the NLRP3 inflammasome [198]. This introduces the possibility of modulating cytokine "storm" by a DRD1 agonist. Fenoldopam is a catecholcontaining DRD1 partial agonist that does not cross the blood-brain barrier. The drug also exerts vasodilator effects in coronary, renal, mesenteric, and peripheral arteries and is used intravenously clinically as an anti-hypertensive agent. The sulfonylurea oral hypoglycemic drug glyburide is a NLPR3 inhibitor [186]; however, effective doses may be high enough to produce cardiovascular side effects.

In patients with sepsis or acute respiratory distress syndrome, high-dose corticosteroid administration does not improve survival; however, low doses of corticosteroids alleviate inflammation and improve survival [29]. A recent news report noted that dexamethasone substantially improved mortality in COVID-19, without reference to a peer-reviewed publication [105].

A randomized, blinded, healthy control pilot trial of noninvasive transcutaneous vagal stimulation reported downregulation of inflammatory cytokine release [106]. Clinical trials of non-invasive vagal stimulation in COVID-19 are currently under way (NCT04382391, NCT04379037).

\section{Conclusions}

Concepts presented here such as the EAS, allostasis, and dyshomeostasis can account for the age-relatedness of COVID-19 mortality and the multi-organ involvement in the disease. These concepts lead to testable hypotheses about biomarkers of risk in COVID-19 and about possible treatments. Ideas are cheap and easy; data are expensive and hard, and the science of COVID-19 and the autonomic nervous system is in its infancy.

Acknowledgement The research reported here was supported (in part) by the Division of Intramural Research, NINDS, NIH.

\section{References}

1. Adams V, Kaufman SR, van Hattum T, Moody S (2011) Aging disaster: mortality, vulnerability, and long-term recovery among Katrina survivors. Med Anthropol 30:247-270
2. Aggarwal S, Garcia-Telles N, Aggarwal G, Lavie C, Lippi G, Henry BM (2020) Clinical features, laboratory characteristics, and outcomes of patients hospitalized with coronavirus disease 2019 (COVID-19): early report from the United States. Diagnosis (Berl) 7:91-96

3. Alpert A, Pickman Y, Leipold M, Rosenberg-Hasson Y, Ji X, Gaujoux R, Rabani H, Starosvetsky E, Kveler K, Schaffert S, Furman D, Caspi O, Rosenschein U, Khatri P, Dekker CL, Maecker HT, Davis MM, Shen-Orr SS (2019) A clinically meaningful metric of immune age derived from high-dimensional longitudinal monitoring. Nat Med 25:487-495

4. Andrews NP, Goldstein DS, Quyyumi AA (1999) Effect of systemic alpha-2 adrenergic blockade on the morning increase in platelet aggregation in normal subjects. Am $\mathbf{J}$ Cardiol 84:316-320

5. Ata F, Almasri H, Sajid J, Yousaf Z (2020) COVID-19 presenting with diarrhoea and hyponatraemia. BMJ Case Rep 7;13(6):e235456. https://doi.org/10.1136/bcr-2020-235456

6. Ayyadurai S, Gibson AJ, D'Costa S, Overman EL, Sommerville LJ, Poopal AC, Mackey E, Li Y, Moeser AJ (2017) Frontline Science: corticotropin-releasing factor receptor subtype 1 is a critical modulator of mast cell degranulation and stress-induced pathophysiology. J Leukoc Biol 102:1299-1312

7. Babapoor-Farrokhran S, Gill D, Walker J, Rasekhi RT, Bozorgnia B, Amanullah A (2020) Myocardial injury and COVID-19: possible mechanisms. Life Sci 253:117723

8. Baines AD (1990) Functional effects of proximal tubular dopamine production. Am J Hypertens 3:68S-71S

9. Baron DN, Green RJ, Khan FA (1985) Adrenaline and ion flux in isolated human leucocytes. Clin Sci 68:517-521

10. Benarroch EE (1993) The central autonomic network: functional organization, dysfunction, and perspective. Mayo Clin Proc 68:988-1001

11. Bergmann M, Sautner T (2002) Immunomodulatory effects of vasoactive catecholamines. Wien Klin Wochenschr 114:752-761

12. Bernard C (1974) Lectures on the phenomena of life common to animals and vegetables. Charles $C$ Thomas, Springfield

13. Bode B, Garrett V, Messler J, McFarland R, Crowe J, Booth $\mathrm{R}$, Klonoff DC (2020) Glycemic characteristics and clinical outcomes of COVID-19 patients hospitalized in the United States. J Diabetes Sci Technol. https://doi.org/10.1177/19322 96820924469

14. Boonen E, Vervenne H, Meersseman P, Andrew R, Mortier L, Declercq PE, Vanwijngaerden YM, Spriet I, Wouters PJ, Vander Perre S, Langouche L, Vanhorebeek I, Walker BR, Van den Berghe G (2013) Reduced cortisol metabolism during critical illness. N Engl J Med 368:1477-1488

15. Breier A, Davis O, Buchanan R, Listwak SJ, Holmes C, Pickar D, Goldstein DS (1992) Effects of alprazolam on pituitaryadrenal and catecholaminergic responses to metabolic stress in humans. Biol Psychiatry 32:880-890

16. Bristow JD, Gribbin B, Honour AJ, Pickering TG, Sleight $P$ (1969) Diminished baroreflex sensitivity in high blood pressure and ageing man. J Physiol 202:45P-46P

17. Brown MJ, Brown DC, Murphy MB (1983) Hypokalemia from beta2-receptor stimulation by circulating epinephrine. N Engl J Med 309:1414-1419

18. Brown MR, Fisher LA, Webb V, Vale WW, Rivier JE (1985) Corticotropin-releasing factor: a physiologic regulator of adrenal epinephrine secretion. Brain Res 328:355-357

19. Brunkard J, Namulanda G, Ratard R (2008) Hurricane Katrina deaths, Louisiana, 2005. Disaster Med Public Health Prep 2:215-223

20. Byer E, Ashman R, Toth LA (1947) Electrocardiogram with large upright T-wave and long Q-T intervals. Am Heart $\mathrm{J}$ 33:796-806 
21. Cai X, Ma Y, Li S, Chen Y, Rong Z, Li W (2020) Clinical characteristics of 5 COVID-19 cases with non-respiratory symptoms as the first manifestation in children. Front Pediatr 8:258

22. Camell CD, Sander J, Spadaro O, Lee A, Nguyen KY, Wing A, Goldberg EL, Youm YH, Brown CW, Elsworth J, Rodeheffer MS, Schultze JL, Dixit VD (2017) Inflammasome-driven catecholamine catabolism in macrophages blunts lipolysis during ageing. Nature 550:119-123

23. Cannon WB (1914) The emergency function of the adrenal medulla in pain and in the major emotions. Am J Physiol 33:356-372

24. Cannon WB (1919) Bodily changes in pain, hunger, fear and rage. D. Appleton \& Co., New York

25. Cannon WB (1939) The wisdom of the body. W.W. Norton, New York

26. Cannon WB (1945) The way of an investigator. W.W. Norton, New York

27. Cannon WB, McIver MA, Bliss SW (1924) A sympathetic and adrenal mechanism for mobilizing sugar in hypoglycemia. Am J Physiol 69:46-66

28. Cannon WB, Querido A, Britton SW, Bright EM (1927) The role of adrenal secretion in the chemical control of body temperature. Am J Physiol 79:466-507

29. Chadda K, Annane D (2002) The use of corticosteroids in severe sepsis and acute respiratory distress syndrome. Ann Med 34:582-589

30. Chan C, Daly M, Melton I, Crozier I (2019) Two major earthquakes in Christchurch were not associated with increased ventricular arrhythmias: analysis of implanted defibrillator diagnostics. PLoS ONE 14:e0216521

31. Chen D, Li X, Song Q, Hu C, Su F, Dai J, Ye Y, Huang J, Zhang $X(2020)$ Assessment of hypokalemia and clinical characteristics in patients with coronavirus disease 2019 in Wenzhou, China. JAMA Netw Open 3:e2011122

32. Chidsey CA, Braunwald E (1966) Sympathetic activity and neurotransmitter depletion in congestive heart failure. Pharmacol Rev 18:685-700

33. Chigr F, Merzouki M, Najimi M (2020) Autonomic brain centers and pathophysiology of COVID-19. ACS Chem Neurosci 11:1520-1522

34. Chikanza IC, Petrou P, Chrousos G (2000) Perturbations of arginine vasopressin secretion during inflammatory stress. Pathophysiologic implications. Ann N Y Acad Sci 917:825-834

35. Christ-Crain M, Hoorn EJ, Sherlock M, Thompson CJ, Wass JAH (2020) Endocrinology in the time of COVID-19: management of diabetes insipidus and hyponatraemia. Eur J Endocrinol 183:G9-G15

36. Chrousos GP, Gold PW (1992) The concepts of stress and stress system disorders. Overview of physical and behavioral homeostasis. J Am Med Assoc 267:1244-1252

37. Clausen $\mathrm{T}$ (1983) Adrenergic control of $\mathrm{Na}+-\mathrm{K}+$-homoeostasis. Acta Med. Scand. Suppl. 672:111-115

38. Colling ME, Kanthi Y (2020) COVID-19-associated coagulopathy: an exploration of mechanisms. Vasc Med. https://doi. org/10.1177/1358863X20932640

39. Daito H, Suzuki M, Shiihara J, Kilgore PE, Ohtomo H, Morimoto K, Ishida M, Kamigaki T, Oshitani H, Hashizume M, Endo W, Hagiwara K, Ariyoshi K, Okinaga S (2013) Impact of the Tohoku earthquake and tsunami on pneumonia hospitalisations and mortality among adults in northern Miyagi, Japan: a multicentre observational study. Thorax 68:544-550

40. Dampney RA, Michelini LC, Li DP, Pan HL (2018) Regulation of sympathetic vasomotor activity by the hypothalamic paraventricular nucleus in normotensive and hypertensive states. Am J Physiol Heart Circ Physiol 315(5):H1200-H1214
41. Danobeitia JS, Sperger JM, Hanson MS, Park EE, Chlebeck PJ, Roenneburg DA, Sears ML, Connor JX, Schwarznau A, Fernandez LA (2012) Early activation of the inflammatory response in the liver of brain-dead non-human primates. J Surg Res 176:639-648

42. Darbar D, Smith M, Morike K, Roden DM (1996) Epinephrineinduced changes in serum potassium and cardiac repolarization and effects of pretreatment with propranolol and diltiazem. Am J Cardiol 77:1351-1355

43. Darling G, Goldstein DS, Stull R, Gorschboth CM, Norton JA (1989) Tumor necrosis factor: immune endocrine interaction. Surgery 106:1155-1160

44. Davy KP, Seals DR, Tanaka H (1998) Augmented cardiopulmonary and integrative sympathetic baroreflexes but attenuated peripheral vasoconstriction with age. Hypertension 32:298-304

45. Diao B, Wang C, Tan Y, Chen X, Liu Y, Ning L, Chen L, Li M, Liu Y, Wang G, Yuan Z, Feng Z, Zhang Y, Wu Y, Chen Y (2020) Reduction and functional exhaustion of $\mathrm{T}$ cells in patients with coronavirus disease 2019 (COVID-19). Front Immunol 11:827

46. Dimopoulou I, Alevizopoulou P, Dafni U, Orfanos S, Livaditi O, Tzanela M, Kotanidou A, Souvatzoglou E, Kopterides P, Mavrou I, Thalassinos N, Roussos C, Armaganidis A, Tsagarakis S (2007) Pituitary-adrenal responses to human corticotropinreleasing hormone in critically ill patients. Intensive Care Med 33:454-459

47. Ding XS, Wu SS, Chen H, Zhao XQ, Li HW (2019) High admission glucose levels predict worse short-term clinical outcome in non-diabetic patients with acute myocardial infraction: a retrospective observational study. BMC Cardiovasc Disord 19:163

48. Dum RP, Levinthal DJ, Strick PL (2016) Motor, cognitive, and affective areas of the cerebral cortex influence the adrenal medulla. Proc Natl Acad Sci USA 113:9922-9927

49. Dum RP, Strick PL (2013) Transneuronal tracing with neurotropic viruses reveals network macroarchitecture. Curr Opin Neurobiol 23:245-249

50. Dusi V, De Ferrari GM, Schwartz PJ (2020) There are 100 ways by which the sympathetic nervous system can trigger life-threatening arrhythmias. Eur Heart J 41:2180-2182

51. Dziewierz A, Giszterowicz D, Siudak Z, Rakowski T, Dubiel JS, Dudek D (2010) Admission glucose level and in-hospital outcomes in diabetic and non-diabetic patients with acute myocardial infarction. Clin Res Cardiol 99:715-721

52. Eisenhofer G, Goldstein DS, Stull RW, Gold PW, Keiser HR, Kopin IJ (1987) Dissociation between corticotrophin and catecholamine responses to isoprenaline in humans. Clin Exp Pharmacol Physiol 14:337-341

53. Eisenhofer G, Rundqvist B, Friberg P (1998) Determinants of cardiac tyrosine hydroxylase activity during exercise-induced sympathetic activation in humans. Am J Physiol 274:R626-R634

54. Esler MD, Thompson JM, Kaye DM, Turner AG, Jennings GL, Cox HS, Lambert GW, Seals DR (1995) Effects of aging on the responsiveness of the human cardiac sympathetic nerves to stressors. Circulation 91:351-358

55. Fathi N, Rezaei N (2020) Lymphopenia in COVID-19: therapeutic opportunities. Cell Biol, Int

56. Fedorowski A (2019) Postural orthostatic tachycardia syndrome: clinical presentation, aetiology and management. J Intern Med 285:352-366

57. Forte G, Favieri F, Tambelli R, Casagrande M (2020) COVID-19 pandemic in the Italian population: validation of a post-traumatic stress disorder questionnaire and prevalence of PTSD symptomatology. Int J Environ Res Public Health 17(11):4151. https://doi. org/10.3390/ijerph17114151

58. Frank SM, Raja SN, Bulcao C, Goldstein DS (2000) Age-related thermoregulatory differences during core cooling in humans. Am J Physiol 279:R349-R354 
59. Friedman B, Cirulli J (2013) Hyponatremia in critical care patients: frequency, outcome, characteristics, and treatment with the vasopressin V2-receptor antagonist tolvaptan. J Crit Care 28(219):e211-e212

60. Fujihara K, Saito A, Heianza Y, Gibo H, Suzuki H, Shimano H, Saito K, Kodama S, Yamada N, Sone H (2012) Impact of psychological stress caused by the Great East Japan Earthquake on glycemic control in patients with diabetes. Exp Clin Endocrinol Diabetes 120:560-563

61. Fukuhara K, Kvetnansky R, Cizza G, Pacak K, Ohara H, Goldstein DS, Kopin IJ (1996) Interrelations between sympathoadrenal system and hypothalamo-pituitary-adrenocortical/thyroid systems in rats exposed to cold stress. J Neuroendocrinol 8:533-541

62. Gagnon N, Mansour S, Bitton Y, Bourdeau I (2017) TakotsuboLike cardiomyopathy in a large cohort of patients with pheochromocytoma and paraganglioma. Endocr Pract 23:1178-1192

63. Galinier M, Pathak A, Fourcade J, Androdias C, Curnier D, Varnous S, Boveda S, Massabuau P, Fauvel M, Senard JM, Bounhoure JP (2000) Depressed low frequency power of heart rate variability as an independent predictor of sudden death in chronic heart failure. Eur Heart J 21:475-482

64. Gaykema RP, Dijkstra I, Tilders FJ (1995) Subdiaphragmatic vagotomy suppresses endotoxin-induced activation of hypothalamic corticotropin-releasing hormone neurons and ACTH secretion. Endocrinology 136:4717-4720

65. Gearhart MM, Parbhoo SK (2006) Hyperglycemia in the critically ill patient. AACN Clin Issues 17:50-55

66. Gill JR Jr (1979) Neural control of renal tubular sodium reabsorption. Nephron 23:116-118

67. Giustino G, Croft LB, Oates CP, Rahman K, Lerakis S, Reddy VY, Goldman M (2020) Takotsubo cardiomyopathy in males with Covid-19. J Am Coll Cardiol. https://doi.org/10.1016/j. jacc.2020.05.06

68. Golczynska A, Lenders JW, Goldstein DS (1995) Glucocorticoid-induced sympathoinhibition in humans. Clin Pharmacol Ther 58:90-98

69. Goldstein DS (1979) The electrocardiogram in stroke: relationship to pathophysiological type and comparison with prior tracings. Stroke 10:253-259

70. Goldstein DS (2006) Adrenaline and the inner world: an introduction to scientific integrative medicine. The Johns Hopkins University Press, Baltimore

71. Goldstein DS (2019) How does homeostasis happen? Integrative physiological, systems biological, and evolutionary perspectives. Am J Physiol Regul Integr Comp Physiol 316:R301-R317

72. Goldstein DS, Bentho O, Park MY, Sharabi Y (2011) Low-frequency power of heart rate variability is not a measure of cardiac sympathetic tone but may be a measure of modulation of cardiac autonomic outflows by baroreflexes. Exp Physiol 96:1255-1261

73. Goldstein DS, Kopin IJ (2008) Adrenomedullary, adrenocortical, and sympathoneural responses to stressors: a meta-analysis. Endo Regul 42:111-119

74. Goldstein DS, McEwen B (2002) Allostasis, homeostats, and the nature of stress. Stress 5:55-58

75. Goldstein DS, Mezey E, Yamamoto T, Aneman A, Friberg P, Eisenhofer G (1995) Is there a third peripheral catecholaminergic system? Endogenous dopamine as an autocrine/paracrine substance derived from plasma DOPA and inactivated by conjugation. Hypertens Res 18(Suppl 1):S93-S99

76. Gordon RD, Kuchel O, Liddle GW, Island DP (1967) Role of the sympathetic nervous system in regulating renin and aldosterone production in man. J Clin Invest 46:599-605

77. Grossman E, Shenkar A, Peleg E, Thaler M, Goldstein DS (1999) Renal effects of L-DOPA in heart failure. J Cardiovasc Pharmacol 33:922-928
78. Gunning WT 3rd, Kvale H, Kramer PM, Karabin BL, Grubb BP (2019) Postural orthostatic tachycardia syndrome is associated with elevated G-protein coupled receptor autoantibodies. J Am Heart Assoc 8:e013602

79. Guyenet PG, Stornetta RL, Bochorishvili G, Depuy SD, Burke PG, Abbott SB (2013) C1 neurons: the body's EMTs. Am J Physiol Regul Integr Comp Physiol 305:R187-R204

80. Guzik TJ, Mohiddin SA, Dimarco A, Patel V, Savvatis K, Marelli-Berg FM, Madhur MS, Tomaszewski M, Maffia P, D’Acquisto F, Nicklin SA, Marian AJ, Nosalski R, Murray EC, Guzik B, Berry C, Touyz RM, Kreutz R, Wang DW, Bhella D, Sagliocco O, Crea F, Thomson EC, McInnes IB (2020) COVID19 and the cardiovascular system: implications for risk assessment, diagnosis, and treatment options. Cardiovasc Res. https:// doi.org/10.1093/cvr/cvaa106

81. Habib MB, Sardar S, Sajid J (2020) Acute symptomatic hyponatremia in setting of SIADH as an isolated presentation of COVID-19. IDCases 21:e00859

82. Haidan A, Bornstein SR, Glasow A, Uhlmann K, Lubke C, Ehrhart-Bornstein M (1998) Basal steroidogenic activity of adrenocortical cells is increased 10-fold by coculture with chromaffin cells. Endocrinology 139:772-780

83. Hamilton A, Zhang Q, Salehi A, Willems M, Knudsen JG, Ringgaard AK, Chapman CE, Gonzalez-Alvarez A, Surdo NC, Zaccolo M, Basco D, Johnson PRV, Ramracheya R, Rutter GA, Galione A, Rorsman P, Tarasov AI (2018) Adrenaline stimulates glucagon secretion by $\mathrm{Tpc} 2$-dependent $\mathrm{Ca}(2+)$ mobilization from acidic stores in pancreatic alpha-cells. Diabetes 67:1128-1139

84. Hashizaki T, Nishimura Y, Teramura K, Umemoto Y, Shibasaki M, Leicht CA, Kouda K, Tajima F (2018) Differences in serum IL-6 response after 1 degrees $C$ rise in core body temperature in individuals with spinal cord injury and cervical spinal cord injury during local heat stress. Int J Hyperth 35:541-547

85. Hasser EM, Bishop VS, Hay M (1997) Interactions between vasopressin and baroreflex control of the sympathetic nervous system. Clin Exp Pharmacol Physiol 24:102-108

86. Hedrington MS, Farmerie S, Ertl AC, Wang Z, Tate DB, Davis SN (2010) Effects of antecedent GABAA activation with alprazolam on counterregulatory responses to hypoglycemia in healthy humans. Diabetes 59:1074-1081

87. Horstmann JP, Marzi I, Relja B (2016) Adrenergic stimulation alters the expression of inflammasome components and interleukins in primary human monocytes. Exp Ther Med 11:297-302

88. Inui A, Kitaoka $\mathrm{H}$, Majima M, Takamiya $\mathrm{S}$, Uemoto $\mathrm{M}$, Yonenaga C, Honda M, Shirakawa K, Ueno N, Amano K, Morita S, Kawara A, Yokono K, Kasuga M, Taniguchi H (1998) Effect of the Kobe earthquake on stress and glycemic control in patients with diabetes mellitus. Arch Intern Med 158:274-278

89. Isnard R, Pousset F, Trochu J, Chafirovskaia O, Carayon A, Golmard J, Lechat P, Thomas D, Bouhour J, Komajda M (2000) Prognostic value of neurohormonal activation and cardiopulmonary exercise testing in patients with chronic heart failure. Am J Cardiol 86:417-421

90. Jan BU, Coyle SM, Oikawa LO, Lu SE, Calvano SE, Lehrer PM, Lowry SF (2009) Influence of acute epinephrine infusion on endotoxin-induced parameters of heart rate variability: a randomized controlled trial. Ann Surg 249:750-756

91. Jezova D, Ochedalski T, Glickman M, Kiss A, Aguilera G (1999) Central corticotropin-releasing hormone receptors modulate hypothalamic-pituitary-adrenocortical and sympathoadrenal activity during stress. Neuroscience 94:797-802

92. Jongen PJ, Stavrakaki I, Voet B, Hoogervorst E, van Munster E, Linssen WH, Sinnige LG, Verhagen WI, Visser LH, van der 
Kruijk R, Verheul F, Boringa J, Heerings M, Gladdines W, Lonnqvist F, Gaillard P (2016) Patient-reported adverse effects of high-dose intravenous methylprednisolone treatment: a prospective web-based multi-center study in multiple sclerosis patients with a relapse. J Neurol 263:1641-1651

93. Jonkers R, Boxtel CJV, Oosterhuis B (1987) B2-adrenoceptormediated hypokalemia and its abolishment by oxprenolol. Clin Pharmacol Ther 42:627-633

94. Karakas M, Haase T, Zeller T (2018) Linking the sympathetic nervous system to the inflammasome: towards new therapeutics for atherosclerotic cardiovascular disease. Eur Heart J 39:70-72

95. Kochi AN, Tagliari AP, Forleo GB, Fassini GM, Tondo C (2020) Cardiac and arrhythmic complications in patients with COVID19. J Cardiovasc Electrophysiol 31:1003-1008

96. Koelsch S, Boehlig A, Hohenadel M, Nitsche I, Bauer K, Sack U (2016) The impact of acute stress on hormones and cytokines, and how their recovery is affected by music-evoked positive mood. Sci Rep 6:23008

97. Koopman FA, Chavan SS, Miljko S, Grazio S, Sokolovic S, Schuurman PR, Mehta AD, Levine YA, Faltys M, Zitnik R, Tracey KJ, Tak PP (2016) Vagus nerve stimulation inhibits cytokine production and attenuates disease severity in rheumatoid arthritis. Proc Natl Acad Sci USA 119:8284-8289

98. Kosiborod M (2018) Hyperglycemia in acute coronary syndromes: from mechanisms to prognostic implications. Endocrinol Metab Clin North Am 47:185-202

99. Kruse HJ, Kreutz R, Staib S, Overlack A, Stumpe KO, Kolloch RE (1994) Dissociation of renin and aldosterone during low-dose epinephrine infusion. Am J Hypertens 7:913-918

100. Kulp GA, Herndon DN, Lee JO, Suman OE, Jeschke MG (2010) Extent and magnitude of catecholamine surge in pediatric burned patients. Shock 33:369-374

101. Lake CR, Ziegler MG, Kopin IJ (1976) Use of plasma norepinephrine for evaluation of sympathetic neuronal function in man. Life Sci 18:1315-1325

102. Langley JN (1903) The autonomic nervous system. Brain 26:1-26

103. Larsson PT, Wallen NH, Egberg N, Hjemdahl P (1992) Alphaadrenoceptor blockade by phentolamine inhibits adrenalineinduced platelet activation in vivo without affecting resting measurements. Clin Sci 82:369-376

104. Larsson PT, Wallen NH, Martinsson A, Egberg N, Hjemdahl P (1992) Significance of platelet beta-adrenoceptors for platelet responses in vivo and in vitro. Thromb Haemost 68:687-693

105. Ledford $H$ (2020) Steroid is first drug shown to prevent death from COVID-19. Nature 582:469

106. Lerman I, Hauger R, Sorkin L, Proudfoot J, Davis B, Huang A, Lam K, Simon B, Baker DG (2016) Noninvasive transcutaneous vagus nerve stimulation decreases whole blood culture-derived cytokines and chemokines: a randomized, blinded, healthy control pilot trial. Neuromodulation 19:283-290

107. Li H, Tian S, Chen T, Cui Z, Shi N, Zhong X, Qiu K, Zhang J, Zeng T, Chen L, Zheng J (2020) Newly diagnosed diabetes is associated with a higher risk of mortality than known diabetes in hospitalized patients with COVID-19. Diabetes Obes, Metab

108. Li H, Yu X, Liles C, Khan M, Vanderlinde-Wood M, Galloway A, Zillner C, Benbrook A, Reim S, Collier D, Hill MA, Raj SR, Okamoto LE, Cunningham MW, Aston CE, Kem DC (2014) Autoimmune basis for postural tachycardia syndrome. J Am Heart Assoc 3:e000755

109. Li Y, Wang B, Zhang LL, He SF, Hu XW, Wong GT, Zhang Y (2016) Dexmedetomidine combined with general anesthesia provides similar intraoperative stress response reduction when compared with a combined general and epidural anesthetic technique. Anesth Analg 122:1202-1210
110. Li YC, Bai WZ, Hashikawa T (2020) The neuroinvasive potential of SARS-CoV2 may play a role in the respiratory failure of COVID-19 patients. J Med Virol 92:552-555

111. Lightman SL, Conway-Campbell BL (2010) The crucial role of pulsatile activity of the HPA axis for continuous dynamic equilibration. Nat Rev Neurosci 11:710-718

112. Lin LY, Wu CC, Liu YB, Ho YL, Liau CS, Lee YT (2001) Derangement of heart rate variability during a catastrophic earthquake: a possible mechanism for increased heart attacks. Pacing Clin Electrophysiol 24:1596-1601

113. Liu X, Zhang R, He G (2020) Hematological findings in coronavirus disease 2019: indications of progression of disease. Ann Hematol 99:1421-1428

114. Long QX, Liu BZ, Deng HJ, Wu GC, Deng K, Chen YK, Liao P, Qiu JF, Lin Y, Cai XF, Wang DQ, Hu Y, Ren JH, Tang N, Xu YY, Yu LH, Mo Z, Gong F, Zhang XL, Tian WG, Hu L, Zhang XX, Xiang JL, Du HX, Liu HW, Lang CH, Luo XH, Wu SB, Cui XP, Zhou Z, Zhu MM, Wang J, Xue CJ, Li XF, Wang L, Li ZJ, Wang K, Niu CC, Yang QJ, Tang XJ, Zhang Y, Liu XM, Li JJ, Zhang DC, Zhang F, Liu P, Yuan J, Li Q, Hu JL, Chen J, Huang AL (2020) Antibody responses to SARS-CoV-2 in patients with COVID-19. Nat Med 26:845-848

115. Long QX, Tang XJ, Shi QL, Li Q, Deng HJ, Yuan J, Hu JL, Xu W, Zhang Y, Lv FJ, Su K, Zhang F, Gong J, Wu B, Liu XM, Li JJ, Qiu JF, Chen J, Huang AL (2020) Clinical and immunological assessment of asymptomatic SARS-CoV-2 infections. Nat Med. https://doi.org/10.1038/s41591-020-0965-6

116. Mariotto S, Savoldi A, Donadello K, Zanzoni S, Bozzetti S, Carta S, Zivelonghi C, Alberti D, Piraino F, Minuz P, Girelli D, Crisafulli E, Romano S, Marcon D, Marchi G, Gottin L, Polati E, Zanatta P, Monaco S, Tacconelli E, Ferrari S (2020) Nervous system: subclinical target of SARS-CoV-2 infection. J Neurol Neurosurg Psychiatry. https://doi.org/10.1136/jnnp-2020-323881

117. Matsukawa T, Sugiyama Y, Watanabe T, Kobayashi F, Mano T (1998) Baroreflex control of muscle sympathetic nerve activity is attenuated in the elderly. J Auton Nerv Syst 73:182-185

118. McClelland E, Amlot R, Rogers MB, Rubin GJ, Tesh J, Pearce JM (2017) Psychological and physical impacts of extreme events on older adults: implications for communications. Disaster Med Public Health Prep 11:127-134

119. Meredith IT, Eisenhofer G, Lambert GW, Dewar EM, Jennings GL, Esler MD (1993) Cardiac sympathetic nervous activity in congestive heart failure. Evidence for increased neuronal norepinephrine release and preserved neuronal uptake. Circulation 88:136-145

120. Meyer P, Degrauwe S, Van Delden C, Ghadri JR, Templin C (2020) Typical takotsubo syndrome triggered by SARS-CoV-2 infection. Eur Heart J 41:1860

121. Mezzacappa ES, Kelsey RM, Katkin ES (1999) The effects of epinephrine administration on impedance cardiographic measures of cardiovascular function. Int J Psychophysiol 31:189-196

122. Mills DCB, Roberts GCK (1967) Effects of adrenaline on human blood platelets. J Physiol 193:443-453

123. Minhas AS, Scheel P, Garibaldi B, Liu G, Horton M, Jennings M, Jones SR, Michos ED, Hays AG (2020) Takotsubo syndrome in the setting of COVID-19 infection. JACC Case Rep 2(9):13211325. https://doi.org/10.1016/j.jaccas.2020.04.023

124. Modlin IM, Champaneria MC, Bornschein J, Kidd M (2006) Evolution of the diffuse neuroendocrine system-clear cells and cloudy origins. Neuroendocrinology 84:69-82

125. Morrison SF (2016) Central control of body temperature. F1000Res 5

126. Nakamura A, Satake H, Abe A, Kagaya Y, Kohzu K, Sato K, Nakajima S, Fukui S, Endo H, Takahashi T, Nozaki E, Tamaki K 
(2013) Characteristics of heart failure associated with the Great East Japan Earthquake. J Cardiol 62:25-30

127. Nakamura M, Tanaka F, Komi R, Tanaka K, Onodera M, Kawakami M, Koeda Y, Sakai T, Tanno K, Onoda T, Matsura Y, Komatsu T, Northern Iwate Heart Registry C (2016) Sustained Increase in the Incidence of acute decompensated heart failure after the 2011 Japan earthquake and tsunami. Am J Cardiol 118:1374-1379

128. Nakano M, Kondo M, Wakayama Y, Kawana A, Hasebe Y, Shafee MA, Fukuda K, Shimokawa H (2012) Increased incidence of tachyarrhythmias and heart failure hospitalization in patients with implanted cardiac devices after the great East Japan earthquake disaster. Circ J 76:1283-1285

129. Nayyar M, Yusuf J, Khan MU, Weber KT (2017) K(+) and $\mathrm{Mg}(2+)$ dyshomeostasis in acute hyperadrenergic stressor states. Am J Med Sci 353:422-424

130. Nesse RM, Williams GC (1994) Why we get sick. The new science of Darwinian medicine. Times Books, New York

131. Niiyama M, Tanaka F, Nakajima S, Itoh T, Matsumoto T, Kawakami M, Naganuma Y, Omama S, Komatsu T, Onoda T, Sakata K, Ichikawa T, Nakamura M (2014) Population-based incidence of sudden cardiac and unexpected death before and after the 2011 earthquake and tsunami in Iwate, northeast Japan. J Am Heart Assoc 3:e000798

132. Ogawa $T$ (1976) Effects of subcutaneously administered adrenaline on human eccrine sweating, with special reference to the physiological significance of the adrenergic sweating mechanism. Jpn J Physiol 26:517-528

133. Oswald GA, Smith CC, Betteridge DJ, Yudkin JS (1986) Determinants and importance of stress hyperglycaemia in non-diabetic patients with myocardial infarction. Br Med J (Clin Res Ed) 293:917-922

134. Palmer GJ, Ziegler MG, Lake CR (1978) Response of norepinephrine and blood pressure to stress increases with age. J Gerontol 33:482-487

135. Papanicolaou DA, Petrides JS, Tsigos C, Bina S, Kalogeras KT, Wilder R, Gold PW, Deuster PA, Chrousos GP (1996) Exercise stimulates interleukin-6 secretion: inhibition by glucocorticoids and correlation with catecholamines. Am J Physiol 271:E601-E605

136. Pasqualetto MC, Secco E, Nizzetto M, Scevola M, Altafini L, Cester A, Rigo F (2020) Stress cardiomyopathy in COVID-19 disease. Eur J Case Rep Intern Med 7:001718

137. Path G, Bornstein SR, Ehrhart-Bornstein M, Scherbaum WA (1997) Interleukin-6 and the interleukin-6 receptor in the human adrenal gland: expression and effects on steroidogenesis. J Clin Endocrinol Metab 82:2343-2349

138. Peeters B, Boonen E, Langouche L, Van den Berghe G (2015) The HPA axis response to critical illness: new study results with diagnostic and therapeutic implications. Mol Cell Endocrinol 408:235-240

139. Penev P, Spiegel K, Marcinkowski T, Van Cauter E (2005) Impact of carbohydrate-rich meals on plasma epinephrine levels: dysregulation with aging. J Clin Endocrinol Metab 90:6198-6206

140. Pietrzak RH, Gallezot JD, Ding YS, Henry S, Potenza MN, Southwick SM, Krystal JH, Carson RE, Neumeister A (2013) Association of posttraumatic stress disorder with reduced in vivo norepinephrine transporter availability in the locus coeruleus. JAMA Psychiatry 70:1199-1205

141. Piira OP, Miettinen JA, Hautala AJ, Huikuri HV, Tulppo MP (2013) Physiological responses to emotional excitement in healthy subjects and patients with coronary artery disease. Auton Neurosci 177:280-285

142. Port JD, Gilbert EM, Larrabee P, Mealey P, Volkman K, Ginsburg R, Hershberger RE, Murray J, Bristow MR (1990)
Neurotransmitter depletion compromises the ability of indirectacting amines to provide inotropic support in the failing human heart. Circulation 81:929-938

143. CfDCa Prevention (2020) Severe outcomes among patients with coronavirus disease 2019 (COVID-19) - United States, February 12-March 16, 2020. Morb Mortal Wkly Rep (MMWR) 69:343-346

144. Rahman F, Pechnik S, Gross D, Sewell L, Goldstein DS (2011) Low frequency power of heart rate variability reflects baroreflex function, not cardiac sympathetic innervation. Clin Auton Res 21:133-141

145. Ranjbar F, Akbarzadeh F, Kazemi B, Ranjbar A, Sharifi Namin S, Sadeghi-Bazargani H (2016) Increased likelihood of arrhythmic events associated with increased anxiety in patients with implanted cardiac defibrillators after the Ahar-Varzegan earthquake in East Azarbaijan, 2012. Bull Emerg Trauma 4:202-210

146. Riegger GA, Liebau G, Kochsiek K (1982) Antidiuretic hormone in congestive heart failure. Am J Med 72:49-52

147. Ritsinger V, Jensen J, Ohm D, Omerovic E, Koul S, Frobert O, Erlinge D, James S, Lagerqvist B, Norhammar A (2019) Elevated admission glucose is common and associated with high shortterm complication burden after acute myocardial infarction: insights from the VALIDATE-SWEDEHEART study. Diab Vasc Dis Res 16:582-584

148. Roca E, Lombardi C, Campana M, Vivaldi O, Bigni B, Bertozzi B, Passalacqua G (2020) Takotsubo syndrome associated with COVID-19. Eur J Case Rep Intern Med 7:001665

149. Rogers JP, Chesney E, Oliver D, Pollak TA, McGuire P, FusarPoli P, Zandi MS, Lewis G, David AS (2020) Psychiatric and neuropsychiatric presentations associated with severe coronavirus infections: a systematic review and meta-analysis with comparison to the COVID-19 pandemic. Lancet Psychiatry 7:611-627

150. Rosas-Ballina M, Ochani M, Parrish WR, Ochani K, Harris YT, Huston JM, Chavan S, Tracey KJ (2008) Splenic nerve is required for cholinergic antiinflammatory pathway control of TNF in endotoxemia. Proc Natl Acad Sci USA 105:11008-11013

151. Rowell LB, Johnson DG, Chase PB, Comess KA, Seals DR (1989) Hypoxemia raises muscle sympathetic activity but not norepinephrine in resting humans. J Appl Physiol 66:1736-1743

152. Rudman D, Moffitt SD, Fernhoff PM, Blackston RD, Faraj BA (1981) Epinephrine deficiency in hypocorticotropic hypopituitary children. J Clin Endocrinol Metab 53:722-729

153. Rundqvist B, Elam M, Bergmann-Sverrisdottir Y, Eisenhofer G, Friberg P (1997) Increased cardiac adrenergic drive precedes generalized sympathetic activation in human heart failure. Circulation 95:169-175

154. Ruzieh M, Batizy L, Dasa O, Oostra C, Grubb B (2017) The role of autoantibodies in the syndromes of orthostatic intolerance: a systematic review. Scand Cardiovasc J 51:243-247

155. Safari S, Eshaghzade M, Najafi I, Baratloo A, Hashemi B, Forouzanfar MM, Rahmati F (2017) Trends of serum electrolyte changes in crush syndrome patients of bam earthquake; a cross sectional study. Emergency 5:e7

156. Scheen AJ, Marre M, Thivolet C (2020) Prognostic factors in patients with diabetes hospitalized for COVID-19: findings from the CORONADO study and other recent reports. Diabetes Metab

157. Schondorf R, Low PA (1993) Idiopathic postural orthostatic tachycardia syndrome: an attenuated form of acute pandysautonomia? Neurology 43:132-137

158. Seals DR, Victor RG, Mark AL (1988) Plasma norepinephrine and muscle sympathetic discharge during rhythmic exercise in humans. J Appl Physiol 65:940-944

159. Selye H (1950) The Physiology and Pathology of Exposure to Stress. A Treatise Based on the Concepts of the 
General-Adaptation Syndrome and the Diseses of Adaptation. Acta, Inc., Montreal, Canada

160. Selye H (1956) The stress of life. McGraw-Hill, New York

161. Selye H (1974) Stress without distress. New American Library, New York

162. Shahid M, Zarif HMA, Farid MS, Abid MS, Akhtar B, Khan MR (2020) Prognostic value of hyperglycemia on admission on in-hospital outcomes in patients presenting with ST-elevation myocardial infarction. Cureus 12:e7024

163. Sherwin RS, Sacca L (1984) Effect of epinephrine on glucose metabolism in humans: contribution of the liver. Am J Physiol 247:E157-E165

164. Singh AK, Singh R (2020) Does poor glucose control increase the severity and mortality in patients with diabetes and COVID19? Diabetes Metab Syndr 14:725-727

165. Siripanthong B, Nazarian S, Muser D, Deo R, Santangeli P, Khanji MY, Cooper LT Jr, Chahal CAA (2020) Recognizing COVID-19-related myocarditis: the possible pathophysiology and proposed guideline for diagnosis and management. Heart Rhythm. https://doi.org/10.1016/j.hrthm.2020.05.001

166. Sleight P, La Rovere MT, Mortara A, Pinna G, Maestri R, Leuzzi S, Bianchini B, Tavazzi L, Bernardi L (1995) Physiology and pathophysiology of heart rate and blood pressure variability in humans: is power spectral analysis largely an index of baroreflex gain? Clin Sci 88:103-109

167. Smyth HS, Sleight P, Pickering GW (1969) Reflex regulation of arterial pressure during sleep in man: quantitative method of assessing baroreflex sensitivity. Circ Res 24:109-121

168. Sternberg EM, Chrousos GP, Wilder RL, Gold PW (1992) The stress response and the regulation of inflammatory disease. Ann Intern Med 117:854-866

169. Struthers AD, Reid JL, Whitesmith R, Rodger JC (1983) Effect of intravenous adrenaline on electrocardiogram, blood pressure, and serum potassium. Br Heart J 49:90-93

170. Sundlof G, Wallin BG (1978) Human muscle nerve sympathetic activity at rest: relationship to blood pressure and age. J Physiol 274:621-637

171. Supiano MA, Hogikyan RV, Morrow LA, Ortiz-Alonso FJ, Herman WH, Galecki AT, Halter JB (1993) Aging and insulin sensitivity: role of blood pressure and sympathetic nervous system activity. J Gerontol 48:M237-M243

172. Sverrisdottir YB, Elam M, Herlitz H, Bengtsson BA, Johannsson G (1998) Intense sympathetic nerve activity in adults with hypopituitarism and untreated growth hormone deficiency. J Clin Endocrinol Metab 83:1881-1885

173. Swanson KV, Deng M, Ting JP (2019) The NLRP3 inflammasome: molecular activation and regulation to therapeutics. Nat Rev Immunol 19:477-489

174. Szatalowicz VL, Arnold PE, Chaimovitz C, Bichet D, Berl T, Schrier RW (1981) Radioimmunoassay of plasma arginine vasopressin in hyponatremic patients with congestive heart failure. $\mathrm{N}$ Engl J Med 305:263-266

175. Tagawa M, Nakamura Y, Ishiguro M, Satoh K, Chinushi M, Kodama M, Aizawa Y (2006) Transient left ventricular apical ballooning developing after the Central Niigata Prefecture Earthquake: two case reports. J Cardiol 48:153-158

176. Tan T, Khoo B, Mills EG, Phylactou M, Patel B, Eng PC, Thurston L, Muzi B, Meeran K, Prevost AT, Comninos AN, Abbara A, Dhillo WS (2020) Association between high serum total cortisol concentrations and mortality from COVID-19. Lancet Diabetes Endocrinol. https://doi.org/10.1016/S2213-8587(20)30216-3

177. Thiele RH, Hucklenbruch C, Ma JZ, Colquhoun D, Zuo Z, Nemergut EC, Raphael J (2015) Admission hyperglycemia is associated with poor outcome after emergent coronary bypass grafting surgery. J Crit Care 30:1210-1216
178. Thomas JA, Marks BH (1978) Plasma norepinephrine in congestive heart failure. Am J Cardiol 41:233-243

179. Thomas SA, Palmiter RD (1997) Thermoregulatory and metabolic phenotypes of mice lacking noradrenaline and adrenaline. Nature 387:94-97

180. Tomar B, Anders HJ, Desai J, Mulay SR (2020) Neutrophils and neutrophil extracellular traps drive necroinflammation in COVID-19. Cells 9(6):E1383. https://doi.org/10.3390/cells90613 83

181. Tonnesen E, Christensen NJ, Brinklov MM (1987) Natural killer cell activity during cortisol and adrenaline infusion in healthy volunteers. Eur J Clin Invest 17:497-503

182. Tracey KJ (2007) Physiology and immunology of the cholinergic antiinflammatory pathway. J Clin Invest 117:289-296

183. Trichopoulos D, Katsouyanni K, Zavitsanos X, Tzonou A, DallaVorgia P (1983) Psychological stress and fatal heart attack: the Athens (1981) earthquake natural experiment. Lancet 1:441-444

184. Varatharaj A, Group CS (2020) Neurological and neuropsychiatric complications of COVID-19 in 153 patients: a UK-wide surveillance study. Lancet Psychiatry. https://doi.org/10.1016/ S2215-0366(20)30287-X

185. Vihonen H, Kuisma M, Salo A, Angerman S, Pietilainen K, Nurmi J (2019) Mechanisms of early glucose regulation disturbance after out-of-hospital cardiopulmonary resuscitation: an explorative prospective study. PLoS ONE 14:e0214209

186. Voet S, Srinivasan S, Lamkanfi M, van Loo G (2019) Inflammasomes in neuroinflammatory and neurodegenerative diseases. EMBO Mol, Med, p 11

187. Wang K, Wu M, Xu J, Wu C, Zhang B, Wang G, Ma D (2019) Effects of dexmedetomidine on perioperative stress, inflammation, and immune function: systematic review and meta-analysis. Br J Anaesth 123:777-794

188. Watson GM, Chan CW, Belluscio L, Doudney K, Lacey CJ, Kennedy MA, Bridgman P (2019) Comparing the variants of takotsubo syndrome: an observational study of the ECG and structural changes from a New Zealand tertiary hospital. BMJ Open 9:e025253

189. Wittstein IS, Thiemann DR, Lima JA, Baughman KL, Schulman SP, Gerstenblith G, Wu KC, Rade JJ, Bivalacqua TJ, Champion HC (2005) Neurohumoral features of myocardial stunning due to sudden emotional stress. N Engl J Med 352:539-548

190. Wolfovitz E, Grossman E, Folio CJ, Keiser HR, Kopin IJ, Goldstein DS (1993) Derivation of urinary dopamine from plasma dihydroxyphenylalanine in humans. Clin Sci 84:549-557

191. Woody A, Figueroa WS, Benencia F, Zoccola PM (2017) Stressinduced parasympathetic control and Its association with inflammatory reactivity. Psychosom Med 79:306-310

192. Wu C, Chen X, Cai Y, Xia J, Zhou X, Xu S, Huang H, Zhang L, Zhou X, Du C, Zhang Y, Song J, Wang S, Chao Y, Yang Z, Xu J, Zhou X, Chen D, Xiong W, Xu L, Zhou F, Jiang J, Bai C, Zheng J, Song Y (2020) Risk factors associated with acute respiratory distress syndrome and death in patients with coronavirus disease 2019 pneumonia in Wuhan, China. JAMA Intern Med

193. Wu J, Huang J, Zhu G, Wang Q, Lv Q, Huang Y, Yu Y, Si X, Yi H, Wang C, Liu Y, Xiao H, Zhou Q, Liu X, Yang D, Guan X, Li Y, Peng S, Sung J, Xiao H (2020) Elevation of blood glucose level predicts worse outcomes in hospitalized patients with COVID-19: a retrospective cohort study. BMJ Open Diabetes Res Care 8(1):e001476. https://doi.org/10.1136/bmjdrc-2020001476

194. Xiao S, Luo D, Xiao Y (2020) Survivors of COVID-19 are at high risk of posttraumatic stress disorder. Glob Health Res Policy 5:29. https://doi.org/10.1186/s41256-020-00155-2

195. Xin JZ, Wu JM, Hu GM, Gu HJ, Feng YN, Wang SX, Cong WW, Li MZ, Xu WL, Song Y, Xiao H, Zhang YY, Wang L (2020) alpha1-AR overactivation induces cardiac inflammation 
through NLRP3 inflammasome activation. Acta Pharmacol Sin 41:311-318

196. Yamabe H, Hanaoka J, Funakoshi T, Iwahashi M, Takeuchi M, Saito K, Kawashima S, Yokoyama M (1996) Deep negative T waves and abnormal cardiac sympathetic image (123I-MIBG) after the Great Hanshin Earthquake of 1995. Am J Med Sci 311:221-224

197. Yamauchi H, Yoshihisa A, Iwaya S, Owada T, Sato T, Suzuki S, Yamaki T, Sugimoto K, Kunii H, Nakazato K, Suzuki H, Saitoh S, Takeishi Y (2013) Clinical features of patients with decompensated heart failure after the Great East Japan Earthquake. Am J Cardiol 112:94-99

198. Yan Y, Jiang W, Liu L, Wang X, Ding C, Tian Z, Zhou R (2015) Dopamine controls systemic inflammation through inhibition of NLRP3 inflammasome. Cell 160:62-73

199. Yang SY, Zhang S, Wang ML (1995) Clinical significance of admission hyperglycemia and factors related to it in patients with acute severe head injury. Surg Neurol 44:373-377
200. Yi C, Zhang C, Hu X, Li Y, Jiang H, Xu W, Lu J, Liao Y, Ma R, Li X, Wang J (2016) Vagus nerve stimulation attenuates myocardial ischemia/reperfusion injury by inhibiting the expression of interleukin-17A. Exp Ther Med 11:171-176

201. Zhang L, Fu P, Wang L, Cai G, Zhang L, Chen D, Guo D, Sun X, Chen F, Bi W, Zeng X, Li H, Liu Z, Wang Y, Huang S, Chen X, Wenchuan earthquake-related AKIsg (2013) Hyponatraemia in patients with crush syndrome during the Wenchuan earthquake. Emerg Med J 30:745-748

202. Zhang XQ, Chen M, Yang Q, Yan SD, de Huang J (2009) Effect of the Wenchuan earthquake in China on hemodynamically unstable ventricular tachyarrhythmia in hospitalized patients. Am J Cardiol 103:994-997

203. Zimlichman R, Goldstein DS, Zimlichman S, Stull R, Keiser HR (1987) Angiotensin II increases cytosolic calcium and stimulates catecholamine release in cultured bovine adrenomedullary cells. Cell Calcium 8:315-325 